\title{
Burnout syndrome and workplace violence among nursing staff: a cross-sectional study
}

\author{
Sirlene Aparecida Scarpin Tsukamoto', Maria José Quina Galdino", Maynara Fernanda Carvalho Barreto"', Júlia Trevisan Martinsı
}

Universidade Estadual de Londrina (UEL), Londrina, Brazil

'MSc. Nurse, Hospital Evangélico de Londrina, Londrina (PR), Brazil; and Member of the Núcleo de Estudos da Saúde do Trabalhador, Universidade Estadual de Londrina (NUESTUEL), Londrina (PR), Brazil.

(D) https://orcid.org/0000-0003-3610-7101

"PhD. Nurse and Adjunct Professor, Department of Nursing, Universidade Estadual do Norte do Paraná (UENP), Bandeirantes (PR), Brazil; and Coordinator, Study Group on Teaching, Health and Work, Universidade Estadual do Norte do Paraná (UENP), Bandeirantes (PR), Brazil. (D) https://orcid.org/0000-0001-6709-3502

"'PhD. Nurse and Professor, Department of Nursing, Universidade Estadual do Norte do Paraná (UENP), Bandeirantes (PR), Brazil; and Member of the Study Group on Teaching, Health and Work, Universidade Estadual do Norte do Paraná (UENP), Bandeirantes (PR), Brazil. (D) https://orcid.org/0000-0002-3562-8477

"vphD. Nurse and Associate Professor, Department of Nursing, Universidade Estadual de Londrina (UEL), Londrina (PR), Brazil; and Coordinator, Study Group on Occupational Health, Universidade Estadual de Londrina (UEL), Londrina (PR), Brazil.

(D) https://orcid.org/0000-0001-6383-7981

KEYWORDS (MeSH terms):

Mental health.

Violence.

Workplace violence.

Exposure to violence.

Physical abuse.

AUTHORS' KEYWORDS:

Mental hygiene.

Violence exposure.

Physical violence.

Physical health-related injuries.

Psychological health-related injuries.

Workplace exhaustion.

\begin{abstract}
BACKGROUND: Among healthcare professionals, nursing workers are the most prone to becoming victims of workplace violence and present the highest burnout levels.

OBJECTIVES: To investigate the association between burnout syndrome and workplace violence among nursing workers.

DESIGN AND SETTING: Cross-sectional study carried out at a teaching hospital in southern Brazil. METHODS: This study involved 242 nursing workers. We collected data over a six-month period using a sociodemographic and occupational survey, the Survey Questionnaire Workplace Violence in the Health Sector and the Maslach Burnout Inventory - General Survey. For occupational violence, we selected the Survey Questionnaire Workplace Violence in the Health Sector. Burnout syndrome was evaluated using the Maslach Burnout Inventory - General Survey. The data were analyzed in the Statistical Package for the Social Sciences (SPSS). Categorical variables were described as absolute and relative frequencies and numerical variables in terms of central trend and dispersion measurements. For data analysis, we applied descriptive statistics and multiple logistic regression.

RESULTS: The multiple models indicated that the workers who had experienced verbal abuse, physical violence and concern about workplace violence over the past 12 months had significantly higher chances of presenting high emotional exhaustion $(P<0.05)$ and depersonalization $(P<0.05)$ and low professional accomplishment $(\mathrm{P}<0.05)$.

CONCLUSION: Occurrence of violence significantly increased the chances of great emotional exhaustion and depersonalization and low professional achievement, within burnout syndrome. Therefore, workplace violence prevention strategies need to be put in place to provide workers with a safe workplace in which to conduct their activities.
\end{abstract}

\section{INTRODUCTION}

Workplace violence has become a worldwide public health problem. ${ }^{1,2}$ All workers are exposed to violence, but healthcare professionals are at potential risk of experiencing physical or verbal abuse while performing their work activities. ${ }^{3}$ Workplace violence is defined as any action, incident or behavior based on a voluntary procedure of the aggressor, as a result of which a professional is assaulted, threatened or suffers any damage or injury during the performance of his or her work, or as a direct result of the work. ${ }^{4}$

The harmful effects of violence on healthcare workers have been acknowledged in both developed and developing countries, ${ }^{5}$ and have become a growing phenomenon. ${ }^{6}$ In 2013 , in the United States, there were around 24,000 cases of workplace violence per year, among which more than $70 \%$ occurred within healthcare services. This finding shows that workplace violence is almost four times more likely to be experienced by healthcare workers than by workers in other sectors. ${ }^{7}$ Physical violence and sexual harassment are more prevalent in Anglo-Saxon countries, and verbal abuse in the Middle East. ${ }^{1,8}$

Workplace violence within healthcare comes from patients, caregivers, physicians and, co-workers and depends on the social characteristics of the subjects and the hospital environment. ${ }^{9}$ Thus, nursing teams, which interact more closely with patients and caregivers and are present in hospitals 24 hours a day, end up being one of the main victims of violence. ${ }^{10}$ In addition, nursing workers are the target of physical, verbal and psychological violent behavior, sexual harassment and lack of support and trust coming from colleagues, superiors and managers. ${ }^{11,12}$ 
When experiencing workplace violence, nursing professionals are predisposed to physical and psychological health-related injuries, which may affect the workers' ability to perform their daily activities. ${ }^{13}$ Violence is related to occurrence of workplace accidents and absenteeism and negatively affects worker satisfaction and recognition. ${ }^{14}$

In addition, violence can affect the entire workforce and consequently impair the quality of care provided to patients and their families. The negative consequences of workplace violence for workers' health have been displayed through symptoms of stress, low self-esteem and discouragement among the victims. These are symptoms that trigger burnout syndrome. ${ }^{15}$

Burnout syndrome is manifested as a prolonged response to chronic interpersonal stressors. This process consists of three dimensions: emotional exhaustion, depersonalization and low professional accomplishment. The meaning of this three-dimensional model is that it clearly places the experience of individual stress within a social context and involves conceptions of oneself and others. As a consequence of the syndrome, work loses its meaning, thereby generating demotivation, negative attitudes and distancing, which cause losses within the health-work process. ${ }^{16}$

Investigating workplace violence and its association with burnout syndrome among nursing professionals is relevant due to the lack of studies on this subject in Latin America. ${ }^{17}$ Thus, the results will enable further knowledge about workplace violence and its relationship with burnout syndrome and can contribute to development of improved violence prevention strategies and decreased workplace exhaustion, which will improve the quality of life in the workplace.

\section{OBJECTIVE}

The objective of this study was to investigate the association between burnout syndrome and workplace violence among nursing workers.

\section{METHODS}

This was a cross-sectional study carried out at a teaching hospital in southern Brazil that offers 313 beds through the Brazilian National Health System (Sistema Único de Saúde, SUS) and provides medium and high-complexity healthcare.

During the study period, the population was composed of 680 nursing workers. To calculate the sample size, a formula for finite populations was used, in which the outcome was taken to be $50 \%$ prevalence and a $95 \%$ confidence interval was assumed. Through this, the minimum number of workers to be included in the study was 242 .

The inclusion criterion for this study was that the subjects needed to have been in their current job for at least one year, in order to avoid bias due to occupational adaptation. Workers who were on holiday or other leave during the data collection period were also excluded.

Data were collected from January to June 2018, through a sociodemographic and occupational survey, which evaluated workplace violence and burnout syndrome. The primary author clarified the purpose of the research and provided the workers with the instrument at the workplaces during their working hours. They were instructed to place the completed questionnaire in a sealed box that was available in all the places where data were collected.

This characterization questionnaire asked for the following sociodemographic data: age (in years), sex (female or male), marital status (single, married, divorced or cohabiting) and schooling (in number of years); and the following occupational data: professional category (nurse or auxiliary nurse/nursing technician), length of service at the institution (in years), weekly workload (in hours, dichotomized as $\leq 36$ hours or $\geq 37$ hours) and work shift (day or night).

To assess occupational violence, we selected the Survey Questionnaire Workplace Violence in the Health Sector, which was developed by the World Health Organization, International Labour and Public Service Organization and International Council of Nursing. ${ }^{18}$ From this instrument, we used the questions about experiences of physical violence, verbal abuse, sexual harassment and other types of violence in the workplace over the previous 12 months. This questionnaire is not a construct that generates a score, which thus allowing analysis on different types of violence separately.

Burnout syndrome was evaluated using the Maslach Burnout Inventory - General Survey (MBI-GS). This is a scale elaborated by Maslach and Jackson, and the Brazilian version was translated by Tamayo in 1997 and validated by Schuster et al. in 2015 . It presents good reliability, with Cronbach's alpha between 0.82 and $0.84 .{ }^{19}$ It is a self-report questionnaire consisting of 16 assertions, accompanied by seven-point Likert-type responses (0-6). The dimension of emotional exhaustion is evaluated by means of six items, depersonalization is evaluated through four items, and low professional accomplishment is evaluated through six items.

The data were analyzed in the Statistical Package for the Social Sciences (SPSS), version 20.0 (IBM, Chicago, Illinois, United States). The categorical variables were described in terms of absolute and relative frequencies and the numerical variables in terms of central trend and dispersion measurements.

The outcomes were the dimensions of the burnout syndrome: emotional exhaustion, depersonalization and professional accomplishment. These were classified as high or low, based on the median. ${ }^{16}$ Associations between these dimensions and workplace violence were initially examined using univariate logistic regression and then unadjusted and adjusted multiple logistic regression. The multiple models were adjusted according to sex, age and work shift, which have been indicated in the literature to be 
control variables. ${ }^{20,21}$ The goodness of fit of the models thus elaborated was verified through the Hosmer-Lemeshow test, in which the higher the alpha value was, the better the fit also was. P-values $<0.05$ were considered statistically significant.

Institutional review board approval was sought and obtained, in accordance with opinion report no. 2.386.855. Licenses to use the MBI-GS were purchased from Mind Garden, which manages the inventory's copyright.

This study was approved by our institution's ethics committee for research involving human subjects in November 2017. Its Brazilian certificate of presentation for ethics assessment (CAAE) number for public consultation is 78866017.1.0000.5231.

\section{RESULTS}

In total, 242 nursing workers aged between 20 and 68 years, and with an average age of 43 years, participated in this study. The majority of them were female (74.4\%), worked as technicians and auxiliary nurses (71.9\%) and developed their work activities during the day (60.7\%) (Table 1).

Physical and verbal violence, sexual harassment and concern about workplace violence were significantly associated with all dimensions of burnout syndrome, except between sexual harassment and depersonalization. High emotional exhaustion was associated with physical violence $(\mathrm{P}<0.001)$, verbal abuse $(\mathrm{P}<0.001)$, sexual harassment $(\mathrm{P}=0.002)$ and concern about workplace violence $(P=0.005)$. High depersonalization was associated with physical violence $(\mathrm{P}<0.001)$, verbal abuse $(\mathrm{P}<0.001)$ and concern about workplace violence $(\mathrm{P}=0.002)$. Low professional accomplishment was associated with physical violence $(\mathrm{P}=0.001)$, verbal abuse $(P=0.001)$, sexual harassment $(P=0.031)$ and concern about workplace violence $(\mathrm{P}=0.002)$ (Table 2$)$.

The multiple models indicated that the workers who had experienced verbal abuse, physical violence and concerns about workplace violence in the past 12 months presented significantly higher chances $(\mathrm{P}<0.034)$ of high emotional exhaustion, high depersonalization and low professional accomplishment. Conversely, sexual harassment was not significantly associated $(\mathrm{P}>0.05)$ with the dimensions of burnout syndrome when the other types of violence were included in the model (Table 3).

\section{DISCUSSION}

The predominance of women in this study was in accordance with data from research carried out in other countries. ${ }^{22,23}$ These data are culturally confirmed in nursing, as women have a series of experiences aimed at the construction of female abilities and skills, one of which is taking care of people; ${ }^{24}$ and the most characteristic and defining attribute of nursing is care.

In relation to female gender and burnout, women may have higher levels of stress and depersonalization in the work
Table 1. Characteristics of study participants

\begin{tabular}{|c|c|c|}
\hline Variables $(n=242)$ & $\begin{array}{c}\text { Mean } \\
\text { (standard } \\
\text { deviation) }\end{array}$ & n (\%) \\
\hline Age (in years) & $43.4(9.4)$ & \\
\hline \multicolumn{3}{|l|}{ Sex } \\
\hline Male & & $62(25.6)$ \\
\hline Female & & $180(74.4)$ \\
\hline \multicolumn{3}{|l|}{ Marital status } \\
\hline Single & & $117(48.3)$ \\
\hline Married & & $125(51.7)$ \\
\hline Education (in years of schooling) & $15.4(3.3)$ & \\
\hline \multicolumn{3}{|l|}{ Professional category } \\
\hline Nurse & & $68(28.1)$ \\
\hline Auxiliary nurse/nursing technician & & $174(71.9)$ \\
\hline Length of service at the institution (in years) & $12.9(9.7)$ & \\
\hline \multicolumn{3}{|l|}{ Weekly workload in hours } \\
\hline$\leq 36$ hours & & $122(50.4)$ \\
\hline$\geq 37$ hours & & $120(49.6)$ \\
\hline \multicolumn{3}{|l|}{ Work shift } \\
\hline Day & & $147(60.7)$ \\
\hline Night & & 95 (39.3) \\
\hline
\end{tabular}

Table 2. Association between workplace violence and the dimensions of burnout syndrome among nursing workers

\begin{tabular}{|c|c|c|c|c|c|c|}
\hline \multirow{3}{*}{$\begin{array}{l}\text { Variables } \\
(n=242)\end{array}$} & \multicolumn{2}{|c|}{$\begin{array}{l}\text { Emotional } \\
\text { exhaustion }\end{array}$} & \multicolumn{2}{|c|}{ Depersonalization } & \multicolumn{2}{|c|}{$\begin{array}{c}\text { Professional } \\
\text { accomplishment }\end{array}$} \\
\hline & high & Derlus & high & D mlun & low & D \\
\hline & n (\%) & P-value & n (\%) & p-value & n (\%) & P-value \\
\hline \multicolumn{7}{|c|}{ Physical violence } \\
\hline No & 75 (38.9) & \multirow{2}{*}{$<0.001$} & $84(43.5)$ & \multirow{2}{*}{$<0.001$} & $97(50.3)$ & \multirow{2}{*}{0.001} \\
\hline Yes & $37(75.5)$ & & $37(75.5)$ & & $38(77.6)$ & \\
\hline \multicolumn{7}{|c|}{ Verbal abuse } \\
\hline No & $26(26.3)$ & \multirow{2}{*}{$<0.001$} & $35(35.4)$ & \multirow{2}{*}{$<0.001$} & $42(42.4)$ & \multirow{2}{*}{0.001} \\
\hline Yes & $86(60.1)$ & & $86(60.1)$ & & $93(65.0)$ & \\
\hline \multicolumn{7}{|c|}{ Sexual harassment } \\
\hline No & $89(42.2)$ & \multirow{2}{*}{0.002} & $101(47.9)$ & \multirow{2}{*}{0.088} & $112(53.1)$ & \multirow{2}{*}{0.031} \\
\hline Yes & $23(74.2)$ & & $20(64.5)$ & & $23(74.2)$ & \\
\hline \multicolumn{7}{|c|}{ Concern about workplace violence } \\
\hline No & $53(38.4)$ & \multirow{2}{*}{0.005} & $57(41.3)$ & \multirow{2}{*}{0.002} & $65(47.1)$ & \multirow{2}{*}{0.002} \\
\hline Yes & $59(56.7)$ & & $64(61.5)$ & & $70(67.3)$ & \\
\hline
\end{tabular}

environment due to their personal characteristics and functions outside of work, such as domestic work. ${ }^{25}$ Regarding the professional category, most participants in the present study were nursing technicians or auxiliary nurses, which is common in the Brazil reality, as these categories represent $80 \%$ of nursing professionals. ${ }^{26}$ In other countries, however, most of them are nurses. ${ }^{27,28,29}$

Currently, many healthcare professionals worldwide report having experienced workplace violence ${ }^{27,30}$ and are consequently presenting psychological illness due to these experiences, such as the burnout syndrome. ${ }^{31}$ These data were verified in this study, in 
Table 3. Influence of workplace violence on the dimensions of burnout syndrome among nursing workers

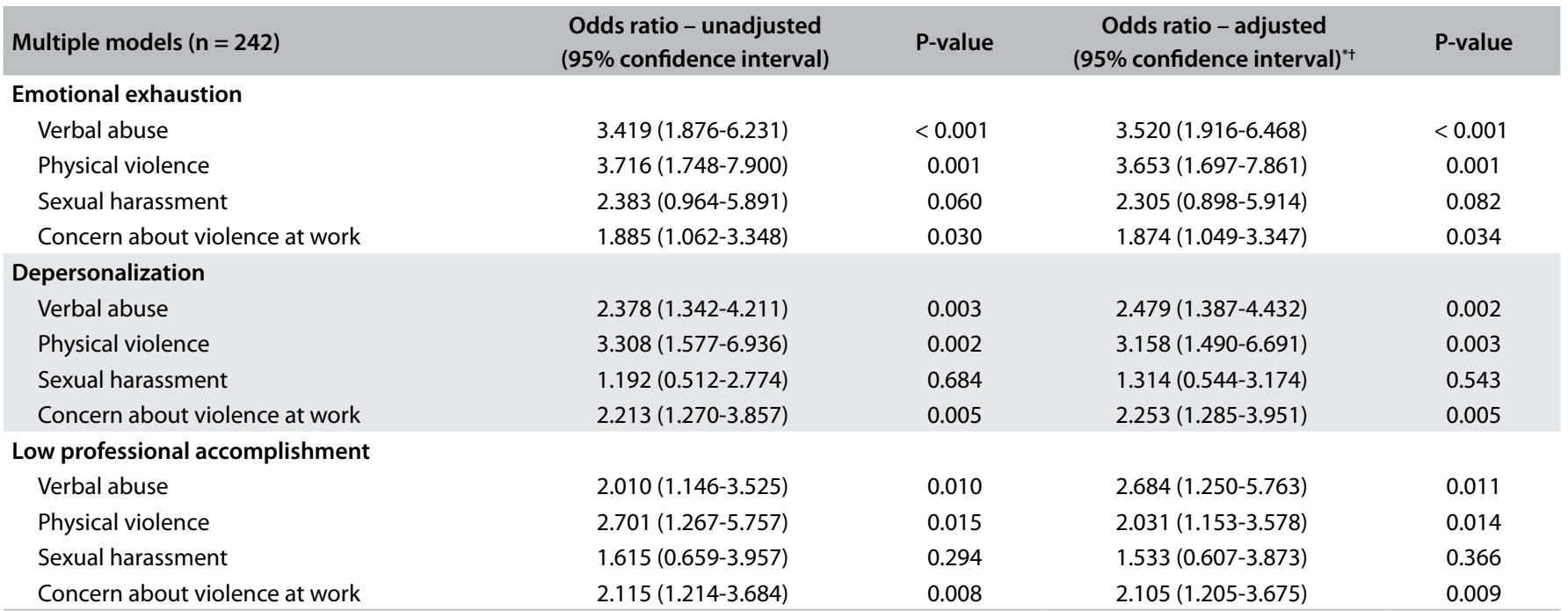

"Adjustment variables: sex, age and work shift; ${ }^{+H}$ osmer-Lemeshow test on adjusted models: $\mathrm{P}=0.712, \mathrm{P}=0.304$ and $\mathrm{P}=0.980$, respectively.

which professionals' experiences of physical and verbal violence were associated with burnout syndrome.

In the United Kingdom, burnout and occupational violence are significant problems, as it has been estimated that $42 \%$ of nurses in that country are considered burned out. ${ }^{32}$ More than 55,000 physical assaults against National Health Service (NHS) teams have been reported, which has led many hospitals to conduct risk assessment actions for service users, educate staff and use safety teams, ${ }^{33}$ which are considered to be effective preventive measures. ${ }^{34}$

Becoming a target of workplace violence has a negative effect on workers' wellbeing ${ }^{35}$ and causes psychological and physical harm, as well as extreme insecurity. These factors contribute to negative sentiments about work. ${ }^{36}$ The ensuing feeling of low personal valuation makes workers experience high levels of stress, ${ }^{37}$ which affect their interpersonal relationships, quality of life and ability to perform daily activities". ${ }^{13}$ This also harms the victims in other regards: spiritually, morally and socially. ${ }^{38}$

In a study among nurses at 11 public hospitals in Spain, greater exposure to workplace violence was associated with greater emotional exhaustion and depersonalization, as well as with lower levels of psychological wellbeing. ${ }^{39}$ Studies conducted in Brazil and Turkey identified that healthcare workers who experienced or were exposed to workplace violence showed high levels of emotional exhaustion and depersonalization and low levels of professional accomplishment, and that workers who were victims of various forms of violence experienced this harm even more strongly. ${ }^{14,40}$ Similar findings were obtained among nurses in Lebanon and Palestine. ${ }^{41,42}$ These results are consistent with the findings obtained from the present study, in which nursing workers who had experienced physical violence and verbal abuse in the previous 12 months showed higher chances of presenting high exhaustion, depersonalization and low professional accomplishment.

Verbal aggression has been found to be the most prevalent among the types of violence that nursing professionals experience. It entails emotional exhaustion that activates a cycle of losses that can lead to dissipation of these individuals' mental and physical resources. Moreover, as a result of perceiving this violence as a threat, workers may adopt an attitude of disengagement, such as depersonalization. ${ }^{43}$

Nursing professionals' exposure to violence tends to contribute to development of a negative and demotivated response to work, which negatively affects their mental health. ${ }^{44}$ This exposure gives rise to feelings of hopelessness, disappointment, fear and anxiety. ${ }^{42}$

A study conducted in 23 hospitals in Guangdong province, in China, among 1,502 nurses, showed that violence in the workplace was directly associated with higher incidence of burnout, lower job satisfaction, lower patient safety and adverse events. Burnout was directly associated with lower patient safety and more adverse events. ${ }^{45}$

Studies in Turkey and Switzerland have shown that nurses who experienced verbal and physical abuse felt a strong desire to leave the profession. The fear that workplace violence will recur makes many of its victims more disposed to breaking their institutional bonds. ${ }^{9,46}$

In the present study, sexual harassment was only a statistically significant correlate when analyzed in isolation from other types of violence. Nonetheless, this link is a cause for concern, given that it did occur among the workers in this analysis. A previous study showed weak correlations between sexual harassment and the dimensions of burnout syndrome. ${ }^{47}$ 
It is a fact that sexual harassment often remains unreported because of its stigmatization. ${ }^{48}$ The traditional nature of hospital environment hierarchies can lead the victims of sexual harassment to ignore it due to shame and the assumption that reporting it will make no difference, especially if the perpetrator is a physician or a boss. ${ }^{49}$ Moreover, in Brazil, the media still attaches a negative stereotype to nursing by presenting the nurse's body as a sexual object. Thus, professional organizations need to mobilize to link the image of nursing to excellent human care delivery and management.

Furthermore, in the present study, concern about workplace violence was associated with high emotional exhaustion, high depersonalization, and low professional accomplishment. According to research conducted in another Brazilian state, only $17.8 \%$ of the interviewees said that they were not worried about violence. ${ }^{50}$

Nursing professionals who have been victims of workplace violence, as well as those who believe that there is a possibility of violence, are worried. Feelings of distress can emerge. Consequently, physical or mental illness may occur. ${ }^{51}$

Thus, it is imperative to ensure the safety of healthcare workers in order to prevent health problems, sick leave and dropout from the job, along with social isolation and the intention to quit this work. ${ }^{14,52}$

There were limitation to this study that related to the self-assessment method used. This may have led to responses that were tailored in accordance with socially acceptable standards. This study was conducted at a public teaching hospital that is rated outstanding because of the high level of medical and nursing care that it makes available in this state in Brazil. Nevertheless, the sample may not have been representative given that convenience sampling was used, which prevents generalization of the results. Additional research is recommended at philanthropic and private hospitals, also focusing on the use of prevention strategies.

Despite these limitations, this study has contributed to advancement of scientific knowledge through revealing information about the different forms of violence that nursing professionals experienced in their workplace and how this problem was associated with burnout syndrome. Thus, it is essential that joint actions in this field should be planned and implemented by nursing workers and managers, in order to promote health and prevent injuries. Such measures should seek to enhance a safe working environment for all parties, and organizational support for these measures should act as a mediator between workplace violence, job satisfaction and burnout levels. ${ }^{53,54}$

\section{CONCLUSION}

Workers who experienced verbal abuse, physical violence and concern about workplace violence in the previous 12 months showed significantly higher chances of high emotional exhaustion, depersonalization and low professional accomplishment.

Workplace violence prevention strategies need to be put in place, including workplace monitoring, so as to stimulate the reporting of violence, promote victim support networks and implement specific pre and post-intervention protocols for the different types of workplace violence, in order provide nursing workers with a safe workplace for development of their activities.

\section{REFERENCES}

1. Spector PE, Zhou EZ, Che XX. Nurse exposure to physical and nonphysical violence, bullying, and sexual harassment: a quantitative review. Int J Nurs Stud. 2014;51(1):72-84. PMID: 23433725; https://doi.org/10.1016/j. ijnurstu.2013.01.010.

2. Krug EG, Dahlberg LL, Mercy JA, Zwi AB, Lozano R. World report on violence and health. World Health Organization, Geneva; 2020. Available from: https://www.who.int/violence_injury_prevention/violence/ world_report/chapters/en/. Accessed in 2020 (Nov 20).

3. Pinar T, Acikel C, Pinar G, et al. Workplace violence in the health sector in Turkey: a national study. J Interpers Violence. 2017;32(15):2345-65. PMID: 26124224; https://doi.org/10.1177/0886260515591976.

4. International Labour Organization. International Council of Nurses, World Health Organization, Public Services International. Framework guidelines for addressing workplace violence in the health sector. OIT, Geneva; 2002. Available from: https://www.lo.org/wcmsp5/groups/ public/---ed_dialogue/---sector/documents/normativeinstrument/ wcms_160908.pdf. Accessed in 2020 (Nov 20).

5. Najafi F, Fallahi-Khoshknab M, Ahmadi F, Dalvandi A, Rahgozar M. Human dignity and professional reputation under threat: Iranian nurses' experiences of workplace violence. Nurs Health Sci. 2016 19(1):44-50. PMID: 27397135; https://doi.org/10.1111/nhs.12297.

6. Anggri NZ, Feng J. Workplace violence against nurses in Indonesian emergency departments. Enferm Clin. 2018;28(Suppl 1):184-90. PMID: 29650182; https://doi.org/10.1016/S1130-8621(18)30064-0.

7. Occupational Safety and Health Administration. Workplace violence in healthcare. OSHA. 2015. Available from: https://www.osha.gov/ Publications/OSHA3826.pdf. Accessed in 2020 (Nov 20).

8. Pourshaikhian M, Abolghasem Gorji H, Aryankhesal A, KhorasaniZavareh D, Barati A. A systematic literature review: workplace violence against emergency medical services personnel. Arch Trauma Res. 2016;5(1):e28734. PMID: 27169096; https://doi.org/10.5812/atr.28734

9. Hahn S, Müller M, Hantikainen V, et al. Risk factors associated with patient and visitor violence in general hospitals: results of a multiple regression analysis. Int J Nurs Stud. 2013;50(3):374-85. PMID: 23102404; https://doi.org/10.1016/j.ijnurstu.2012.09.018.

10. Palagi S, Noguez PT, Amestoy SC, Porto AR. Violence at work: view of nurses of an urgency and an emergency service. J Nurs UFPE. 2015;9(11):970612. https://doi.org/10.5205/1981-8963-v9i11a10759p9706-9712-2015.

11. Hutchinson M, Jackson D. Hostile clinician behaviours in the nursing work environment and implications for patient care: A mixed methods systematic review. BMC Nurs. 2013;12(25). PMID: 24094243; http://doi. org/10.1186/1472-6955-12-25. 
12. Park $\mathrm{M}, \mathrm{Cho} \mathrm{SH}, \mathrm{Hong} H \mathrm{HJ}$. Prevalence and perpetrators of workplace violence by nursing unit and the relationship between violence and the perceived work environment. J Nurs Scholarsh. 2015;47(1):87-95. PMID: 25352254; https://doi.org/10.1111/jnu.12112.

13. Bordignon M, Monteiro MI. Violence in the workplace in Nursing: consequences overview. Rev Bras Enferm. 2016;69(5):996-9. PMID: 27783746; https://doi.org/10.1590/0034-7167-2015-0133.

14. Dal Pai D, Lautert L, Souza SBC, Marziale MHP, Tavares JP. Violence, burnout and minor psychiatric disorders in hospital work. Rev Esc Enferm USP. 2015;49(3):457-64. PMID:26107707; https://doi.org/10.1590/ S0080-623420150000300014.

15. Edward KL, Ousey K, Warelow $P$, Lui S. Nursing and aggression in the workplace: a systematic review. Br J Nurs. 2014;23(12):653-4, 656-9. PMID: 25039630; https://doi.org/10.12968/bjon.2014.23.12.653.

16. Maslach C, Leiter MP. Understanding the burnout experience: recent research and its implications for psychiatry. World Psychiatry. 2016;15(2):103-11.PMID:27265691; https://doi.org/10.1002/wps.20311.

17. Palma A, Ansoleaga E, Ahumada M. Violencia laboral en trabajadores del sector salud: revisión sistemática. Rev Med Chile. 2018;146:213-22. PMID: 29999158; https://doi.org/10.4067/s0034-98872018000200213.

18. Di Martino V. Workplace violence in the health sector - country case studies: Brazil, Bulgarian, Lebanon, Portugal, South Africa, Thailand, plus an additional Australian study: synthesis report. WHO, Geneva. 2003. Available from: https://www.who.int/violence_injury_prevention/ injury/en/WVsynthesisreport.pdf. Accessed in 2020 (Nov 20).

19. Schuster MS, Dias VV, Battistella LF, Grohmann MZ. MBI-GS scale validation: a general survey investigation on employees' health perception. REGE Revista de Gestão. 2015;22(3):403-16. https://doi. org/10.5700/rege569.

20. Maslach C, Jackson SE. The measurement of experienced burnout. J Occup Behav. 1981;2(2):99-103. https://doi.org/10.1002/job.4030020205.

21. Vidotti V, Ribeiro RP, Galdino MJQ, Martins JT. Burnout syndrome and shift work among the nursing staff. Rev Latino-Am Enfermagem. 2018;26:e3022. https://doi.org/10.1590/1518-8345.2550.3022.

22. Chen X, Lv M, Wang M, et al. Incidence and risk factors of workplace violence against nurses in a Chinese top-level teaching hospital: a cross-sectional study. Appl Nurs Res. 2018;40:122-28. PMID: 29579486; https://doi.org/10.1016/j.apnr.2018.01.003.

23. Shafran-Tikva S, Zelker R, Stern Z, Chinitz D. Workplace violence in a tertiary care Israeli hospital - a systematic analysis of the types of violence, the perpetrators and hospital departments. Isr J Health Policy Res. 2017;6(1):43. PMID: 28835267; https://doi.org/10.1186/s13584-017-0168-x.

24. Almeida DB, Queirós PJP, Silva GTR, Laitano AC, Almeida SS. Sexist stereotypes in Portuguese nursing: A historical study in the period 1935 to 1974. Esc Anna Nery. 2016;20(2):228-35. https://doi.org10.5935/14148145.20160030

25. Paiva LC, Canário ACG, China ELCP, Gonçalves AK. Burnout syndrome in health-care professionals in a university hospital. Clinics. 2017;72(5):3059. PMID: 28591343. https://doi.org/10.6061/clinics/2017(05)08.
26. Machado MH, Aguiar Filho W, Lacerda WF, et al. Overall characteristics of the nursing profession: sociodemographic profile. Enferm Foco. 2016;6(1):11-7.

27. Zhang L, Wang A, Xie $X$, et al. Workplace violence against nurses: a cross-sectional study. Int J Nurs Stud. 2017;72:8-14. PMID: 28412581; https://doi.org/10.1016/j.ijnurstu.2017.04.002.

28. Fasanya BK, Dada EA. Workplace violence and safety issues in long-term medical care facilities: nurses perspectives. Saf Health Work. 2016;7(2):97101. PMID: 27340595; https://doi.org/10.1016/j.shaw.2015.11.002.

29. Speroni KG, Fitch T, Dawson E, Dugan L, Atherton M. Incidence and cost of nurse workplace violence perpetrated by hospital patients or patient visitors. J Emerg Nurs. 2014;40(3):218-28. PMID: 24054728; https://doi.org/10.1016/j.jen.2013.05.014.

30. Duncan SM, Hyndman K, Estabrooks CA, et al. Nurses' experience of violence in Alberta and British Columbia Hospitals. Can J Nurs Res. 2001;32(4):57-78

31. Kim H, Kim JS, Choe K, Kwak Y, Song JS. Mediating effects of workplace violence on the relationships between emotional labour and burnout among clinical nurses. J Adv Nurs. 2018;74(10):2331-9. PMID: 29869815; https://doi.org/10.1111/jan.13731.

32. Royal College of Nursing. Beyond Breaking Point. RCN, London. 2013. Available from: https://www2.rcn.org.uk/_data/assets/pdf_ file/0005/541778/004448.pdf. Accessed in 2020 (Nov 20).

33. Design Council. Reducing violence and aggression in A\&E through a better experience. Department of Health, London. 2011. Available from: https://www.designcouncil.org.uk/sites/default/files/asset/document/ ReducingViolenceAndAggressionInAandE.pdf. Accessed in 2020 (Nov 20).

34. Morphet J, Griffiths D, Beattie J, Velasquez Reyes D, Innes K. Prevention and management of occupational violence and aggression in healthcare: A scoping review. Collegian. 2018;25:621-32. https://doi. org/10.1016/j.colegn.2018.04.003.

35. Portoghese I, Galletta M, Leiter MP, Cocco P, D'Aloja E, Campagna M. Fear of future violence at work and job burnout: A diary study on the role of psychological violence and job control. Burnout Res. 2017;7:36-46. https://doi.org/10.1016/j.burn.2017.11.003.

36. Shi $L$, Wang $L$, Jia $X$, et al. Prevalence and correlates of symptoms of posttraumatic stress disorder among Chinese healthcare workers exposed to physical violence: a cross-sectional study. BMJ Open. 2017;7(7):e016810. https://doi.org/10.1136/bmjopen-2017-016810.

37. Magnavita N. Workplace violence and occupational stress in healthcare workers: a chicken-and-egg situation-results of a 6-year follow-up study. J Nurs Scholarsh. 2014;46(5):366-76. PMID: 24754800; http:// doi.org/10.1111/jnu.12088.

38. Al-Omari H. Physical and verbal workplace violence against nurses in Jordan. Int Nurs Rev. 2015;62(1):111-8. PMID: 25626758; https://doi. org/10.1111/inr.12170

39. Waschgler K, Ruiz-Hernández JA, Llor-Esteban B, García-Izquierdo M. Patients' aggressive behaviours towards nurses: development and psychometric properties of the hospital aggressive behaviour scale- 
users. J Adv Nurs. 2013;69(6):1418-27. PMID: 22998592; https://doi. org/10.1111/jan.12016.

40. Erdur B, Ergin A, Yüksel A, et al. Assessment of the relation of violence and burnout among physicians working in the emergency departments in Turkey. Ulus Travma Acil Cerrahi Derg. 2015;21(3):175-81. PMID: 26033649; https://doi.org/10.5505/tjtes.2015.91298.

41. Alameddine M, MouradY, Dimassi H. A national study on nurses exposure to occupational violence in Lebanon: prevalence, consequences and associated factors. Plos One. 2015;10(9):e0137105. PMID: 26355686; https://doi.org/10.1371/journal.pone.0137105.

42. Hamdan M, Hamra AA. Workplace violence towards workers in the emergency departments of Palestinian hospitals: a cross-sectional study. Hum Resour Health. 2015;13:28. PMID: 25948058; https://doi. org/10.1186/s12960-015-0018-2.

43. Viotti S, Gilardi S, Guglielmetti C, Converso D. Verbal aggression from care recipients as a risk factor among nursing staff: a study on Burnout in the JD-R model perspective. Biomed Res Int. 2015;2015:215267. PMID: 26568956; https://doi.org/10.1155/2015/215267.

44. Hamdan M, Hamra AA. Burnout among workers in emergency Departments in Palestinian associated factors. BMC Health Serv Res. 2017;17:407. PMID:28619081; https://doi.org/10.1186/s12913-017-2356-3.

45. Lui J, Zheng J, Liu K, et al. Workplace violence against nurses, job satisfaction, burnout, and patient safety in Chinese hospitals. Nurs Outlook. 2019;67:558-66. PMID: 31202444. https://doi.org/10.1016/j. outlook.2019.04.006

46. Ünsal Atan S, Baysan Arabaci L, Sirin A, et al. Violence experienced by nurses at six university hospitals in Turkey. J Psychiatr Ment Health Nurs. 2013; 20(10):882-9. PMID: 23216948; https://doi.org/10.1111/jpm.12027.

47. Yang BX, Stone TE, Petrini MA, Morris DL. Incidence, type, related factors, and effect of workplace violence on mental health nurses: cross-sectional survey. Arch Psychiatr Nurs. 2018;32(1):31-8. PMID: 29413069; https://doi.org/10.1016/j.apnu.2017.09.013.

48. Donne MD, DeLuca J, Pleskach P, et al. Barriers to and facilitators of help-seeking behavior among men who experience sexual violence. Am J Mens Health. 2018;12(2):189-201. PMID: 29161934; https://doi. org/10.1177/1557988317740665.

49. Nelson R. Sexual harassment in nursing: a long-standing, but rarely studied problem. Am J Nurs. 2018;1 18(5):19-20. PMID:29698272; https:// doi.org/10.1097/01.NAJ.0000532826.47647.42.

50. Silva IV, Aquino EML, Pinto ICM. Workplace violence in the healthcare sector: the experience of State health employees in Bahia State, Brazil. Cad Saude Publica. 2014;30(10):2112-22. PMID: 25388314; https://doi. org/10.1590/0102-311X00146713.

51. Santos AMR, Soares JCN, Nogueira LF, et al. Institutional violence: routine experiences of the nursing team. Rev Bras Enferm. 2011; 64(1):84-90. PMID: 21468494; https://doi.org/10.1590/S0034-71672011000100013.
52. Costa ICP, Costa SFG, Andrade CG, et al. Scientific production on workplace bullying/harassment in dissertations and theses in the Brazilian scenario. Rev Esc Enferm USP. 2015;49(2):267-76. PMID: 25992826; https://doi.org/10.1590/S0080-623420150000200012.

53. LiuW, Zhao S, Shi L, et al. Workplace violence, job satisfaction, burnout, perceived organizational support and their effects on turnover intention among Chinese nurses in tertiary hospitals: a cross-sectional study. BMJ Open. 2018;8:e019525. https://doi.org/10.1136/bmjopen-2017-019525.

54. Wu Y, Wang J, Liu J, et al. The impact of work environment on workplace violence, burnout and work attitudes for hospital nurses: A structural equation modelling analysis. J Nurs Manag. 2020;28:495-503. PMID: 31891429; https://doi.org/10.1111/jonm.12947.

Authors' contributions: Tsukamoto SAS: conceptualization (lead), data curation (lead), formal analysis (lead), investigation (lead), methodology (lead), project administration (equal), resources (lead), software (equal), validation (equal), visualization (lead), writing-original draft (lead) and writing-review and editing (lead); Galdino MJQ: data curation (equal), formal analysis (equal), methodology (equal), software (equal), validation (equal), writing-original draft (equal) and writing-review and editing (equal); Barreto MFC: formal analysis (supporting), methodology (supporting), validation (supporting) and writing-review and editing (equal); and Martins JT: conceptualization (equal), data curation (equal), formal analysis (equal), investigation (equal), methodology (supporting), project administration (equal), resources (equal), software (equal), supervision (equal), validation (equal), visualization (equal), writingoriginal draft (equal) and writing-review and editing (equal). All authors actively contributed to discussion of the results from the study, and reviewed and approved the final version to be released

Sources of funding: No support or funding source was received for development of this study

Conflict of interest: The authors declare that they did not have any conflict of interest

Date of first submission: January 25, 2021

Last received: May 19, 2021

Accepted: May 31, 2021

\section{Address for correspondence:}

Maynara Fernanda Carvalho Barreto

Rodovia BR-369 Km 54, Vila Maria, CP 261

Bandeirantes (PR) - Brasil

CEP 86360-000

Tel. (+55 43) 99613-2264

E-mail: maynara_barreto@hotmail.com 